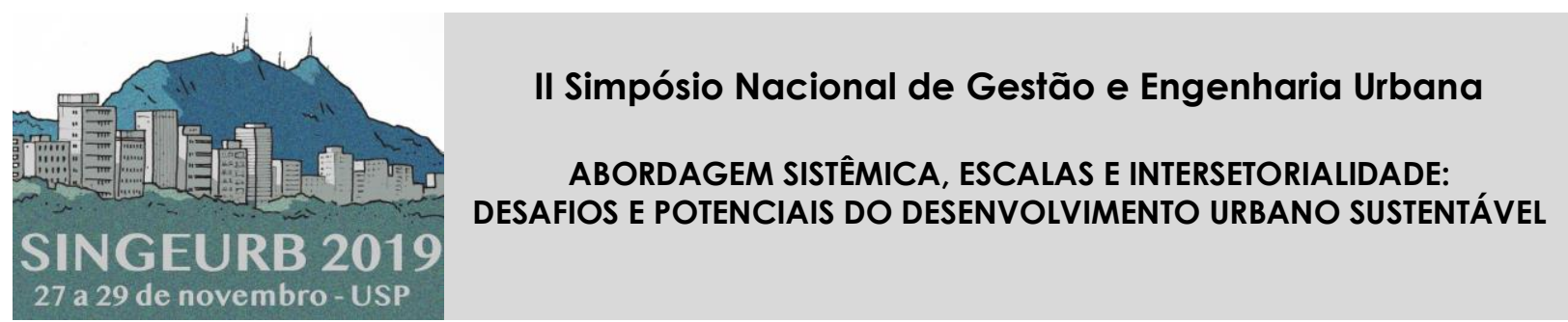

\title{
Análise da acessibilidade de áreas internas e externas de ginásios de escolas públicas de Chapecó (SC)'
}

\section{Analysis of accessibility of internal and external areas of public schools gymnasiums in Chapecó (SC) ${ }^{1}$}

\author{
Castegnera, Ariane 1; Sabka, Vanessa 2; Manfroi, Eliz Paula ${ }^{3}$ \\ 1 Universidade Comunitária da Região de Chapecó - UNOCHAPECÓ, \\ Servidão Anjo da Guarda, 295-D, Bairro: Efapi, Chapecó - SC, Brasil, \\ castegnera@unochapeco.edu.br \\ 2 UNOCHAPECÓ, vanessasabka@unochapeco.edu.br \\ 3 UNOCHAPECÓ, eng_eliz@unochapeco.edu.br
}

\begin{abstract}
RESUMO
A acessibilidade nas edificações é um direito fundamental do cidadão para uso com segurança dos espaços públicos ou privados. Todos os locais devem apresentar acesso para pessoas portadoras de deficiência ou com mobilidade reduzida. A falta de acessibilidade em ginásios esportivos dificulta a prática de esportes, bem como a possibilidade de participação em eventos realizados nestes ambientes. Neste contexto, na presente pesquisa, foi realizada a avaliação da acessibilidade das áreas internas e externas de ginásios de 10 escolas públicas do município de Chapecó (SC), sendo 6 estaduais e 4 municipais. Para o desenvolvimento deste estudo foram realizadas visitas técnicas e aplicação de um checklist com base nas normas técnicas brasileiras sobre acessibilidade. Os resultados mostraram que nenhum ginásio avaliado apresentou acessibilidade total. Ainda, os ginásios das escolas estaduais apresentaram melhor desempenho de acessibilidade quando comparados com os ginásios das escolas municipais. A falta de acessibilidade nas áreas internas e externas dos ginásios das escolas públicas do município de Chapecó (SC) dificulta a participação de todos os cidadãos nestes locais, não garantindo a liberdade de locomoção em segurança.
\end{abstract}

Palavras-chave: acessibilidade, ginásio, escolas.

\begin{abstract}
Accessibility in buildings is a fundamental right of the citizen to use public or private spaces with safety. All places must have access for people with disabilities or with reduced mobility. The lack of accessibility in sports gymnasiums makes it difficult to practice sports, as well as the possibility to take part in events held in these environments. In this context, the present study evaluated the accessibility of internal and external gymnasiums in 10 public schools in the city of Chapecó (SC), where 6 belong to the state and 4 to the municipality. For the development of this study were carried out technical visits and the application of a checklist based on Brazilian technical standards on accessibility. The results showed that none of the gymnasium

${ }^{1}$ CASTEGNERA, Ariane; SABKA, Vanessa; MANFROI, Eliz Paula. Análise da acessibilidade de áreas internas e externas de ginásios de escolas públicas de Chapecó (SC). In: II SIMPÓSIO NACIONAL DE GESTÃO E ENGENHARIA URBANA: SINGEURB, 2019, São Paulo. Anais... Porto Alegre: ANTAC, 2019.
\end{abstract}


that was evaluated had total accessibility. Still, the gymnasiums of the state presented better accessibility performance when compared to the ones of the municipal schools. The lack of accessibility in the internal and external areas of the public school gymnasiums in the municipality of Chapecó (SC) makes it difficult for all citizens to take part in these places, not guaranteeing freedom of movement in safety.

Keywords: accessibility, gymnasium. Schools.

\section{INTRODUÇÃO}

Em 1980, se iniciaram no Brasil discussões acerca da acessibilidade, organizadas por movimentos sociais de pessoas portadoras de deficiência. Em resposta a esses movimentos, foi elaborada a primeira norma em 1994, a NBR 9050, que serviu como base para a criação de novos projetos, estabelecendo padrões e parâmetros para os ambientes mais adequados, com estruturas mais acessíveis, eliminando assim as barreiras arquitetônicas que dificultam o acesso de pessoas portadoras de deficiência física, auditiva, visual ou com mobilidade reduzida (GADELHA, 2011).

Para Muzzillo (2016), o direito de ir e vir dos indivíduos em locais públicos é universal, sendo assim, é necessário que os ambientes estejam preparados para recebê-los. Porém, a falta de acessibilidade nestes ambientes ultrapassa as barreiras físicas, causando constrangimentos perante a sociedade, impossibilitando a participação delas no âmbito social.

De acordo com Mazzotta (2011), quando existem obstáculos para o acesso de pessoas em locais sociais e culturais, há uma privação de liberdade e igualdade. O autor ainda salienta que a acessibilidade não é somente ter acesso ao local, e sim, o direito de participar ativamente nesse meio.

Segundo Bernal (2012), torna-se desestimulante a prática de atividades físicas, pela falta de acessibilidade nos locais, seja em ginásios de escolas ou clubes esportivos. Porém, se criado um ambiente adequado, com as sinalizações e dimensões que possibilitam a circulação de pessoas com mobilidade reduzida, sem o auxílio de qualquer outra, a prática de esporte se torna estimulante e prazerosa.

Para Andrade (2009), a cultura física é um direito de todos os cidadãos, entretanto, para que se cumpram estes direitos, os espaços desportivos, incluindo ginásios e clubes recreativos, deverão estar adequados, atendendo simultaneamente às diferentes necessidades de cada pessoa.

A Lei $n^{\circ} 10.098$ de 19 de dezembro de 2000 determina que construção e/ou reforma de ginásios/clubes esportivos, sejam públicos ou privados, destinado para jogos, deverão ser executados garantindo a acessibilidade de para-atletas, pessoas com mobilidade reduzida e portadoras de deficiência, adaptando as áreas comuns, como banheiros e vestiários.

Portanto, esta pesquisa propôs avaliar a acessibilidade das áreas internas e externas dos ginásios de esportes de escolas públicas de Chapecó, conforme a NBR 9050 (ABNT, 2015) e a NBR 16537 (ABNT, 2016), a fim de propor melhorias a serem realizados pelos órgãos responsáveis pela infraestrutura dos ginásios esportivos das escolas municipais e estaduais, podendo adaptar os locais tornando os direitos iguais a todos os cidadãos.

\section{MATERIAIS E MÉTODOS}

Nesta pesquisa foi avaliada a acessibilidade das áreas internas e externas dos ginásios das escolas públicas de Chapecó (SC) no segundo semestre de 2018, sendo 6 estaduais e 4 municipais. As mesmas foram escolhidas aleatoriamente e identificadas de A a $F$ (estaduais) e G a J (municipais).

Para a avaliação da acessibilidade, foi elaborado um checklist adaptado da cartilha do CREA - SC (2017), baseado nas normas NBR 9050 (ABNT, 2015) e NBR 16537 (ABNT, 2016), sendo avaliados os seguintes itens de acessibilidade: 
- Pisos táteis das calçadas de acesso aos ginásios: existência de desníveis e riscos permanentes, orientação de maneira segura, informação de mudança de direção, se são contínuas ou antiderrapantes, luminância de contraste do piso, largura e contraste do piso, mudanças de direção, largura das faixas e mudança de direção no encontro de faixas;

- Calçadas dos acessos aos ginásios: largura mínima de 1,20 m, revestimento do piso, largura das faixas de serviço de $0,70 \mathrm{~m}$, existência de obstáculos interferindo na calçada, obstáculos aéreos, rebaixamento de calçada, largura e inclinação das rampas, existência de faixa de travessia de pedestre na frente da rampa, sinalização tátil de alerta com textura e cor diferente da calçada.

- Travessias dos acessos aos ginásios: se em rebaixamentos de calçadas havia sinalização tátil de alerta perpendicular à linha de caminhamento ou paralela à faixa de travessia de pedestres, se as sinalizações táteis de alerta estavam paralelas às faixas elevadas de travessias, orientação e deslocamento de uma faixa para outra, travessia elevada com o mesmo nível da calçada;

- Mobiliário urbano dos acessos aos ginásios: localização, sinalização entorno do mobiliário, alturas dos telefones públicos, segurança e se estão instalados fora da faixa livre de circulação;

- Corredores: largura e comprimento dos corredores de acessos aos banheiros dos ginásios;

- Sanitários: existência de sanitário acessível, localização, sinalização indicando circulação adequada, presença das barras de apoio, alturas dos sanitários, vão livre das portas e fecho das mesmas, altura do lavatório e tipo do piso.

Como as escolas $\mathrm{F}$ e J não tinham acesso direto para o ginásio e era necessário entrar pela entrada principal da escola, foram consideradas estas calçadas como calçadas de acesso aos ginásios.

Foi realizado o registro fotográfico das áreas externas como calçadas, pisos táteis, mobiliário urbano e travessias e nas áreas internas dos corredores e banheiros. Em alguns lugares se fez necessária a utilização de trena para medição.

Para a avaliação de cada item do checklist foi assinalado "sim" quando os itens estavam de acordo com as normas, com "não" quando não estavam de acordo e com "não se aplica" quando não havia necessidade da presença do item no local avaliado.

Após a aplicação do checklist, realizou-se o registro por notas, adaptado da lista de verificação de Saurin e Formoso (2006).

- Pontos Obtidos (PO): corresponde ao total de itens com avaliação positiva de cada item avaliado no checklist;

- Pontos Possíveis (PP): corresponde ao total de itens com avaliação positiva ou negativa de cada item avaliado no checklist;

- Para os fins de atribuição foram desconsiderados os itens marcados com "não se aplica", pois estes itens não se faziam necessários.

Para calcular o resultado da avaliação, por meio da Equação (1).

Nota $=\frac{p o}{p p} .10$ 
Quadro 1 - Desempenho da acessibilidade

\begin{tabular}{|c|c|}
\hline Desempenho & Nota \\
\hline Excelente & 10 \\
\hline Bom & 8 a 9 \\
\hline Regular & 6 a 7 \\
\hline Ruim & 4 a 5 \\
\hline Péssimo & Até 3 \\
\hline
\end{tabular}

Fonte: Os autores

\section{COMPARATIVO DA ACESSIBILIDADE DAS ÁREAS INTERNAS E EXTERNAS DOS GINÁSIOS DAS ESCOLAS MUNICIPAIS E ESTADUAIS DE CHAPECÓ-(SC)}

A Figura 1 compara o desempenho da acessibilidade das escolas municipais e estaduais no item calçadas de acesso aos ginásios, sendo que $75 \%$ das escolas municipais classificou-se como péssima, e as estaduais com $50 \%$ ruim. Apesar de nenhuma atender às condições mínimas de acessibilidade estabelecidas pela norma, as calçadas de acesso aos ginásios das escolas estaduais apresentaram melhor desempenho de acessibilidade quando comparadas com as calçadas de acesso aos ginásios das escolas municipais.

Figura 1 - Acessibilidade das calçadas de acesso aos ginásios das escolas

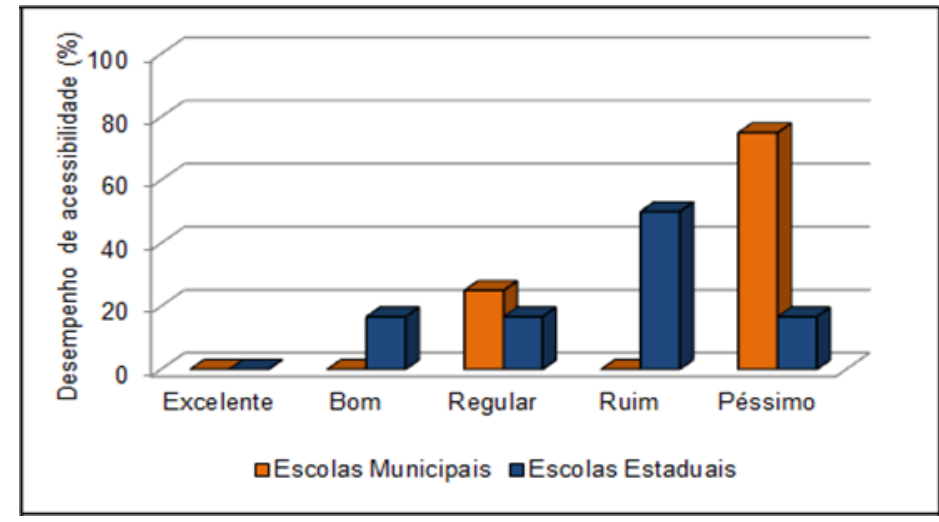

Fonte: Ariane e Vanessa (2018)

A Figura 2 mostra o desempenho de acessibilidade dos pisos táteis das calçadas de acesso aos ginásios das escolas, sendo que as estaduais demonstraram melhor desempenho que as municipais, pois obtiveram como desempenho de acessibilidade: 16,67\% bom, 33,33\% regular e, $50 \%$ péssimo. As escolas municipais apresentaram $75 \%$ de condições péssimas dos pisos táteis, devido principalmente à falta de sinalização de alerta no piso e desníveis acentuados na sinalização direcional.

A Figura 3 apresenta o desempenho de acessibilidade das travessias de acesso aos ginásios das escolas, sendo que o acesso das escolas municipais neste item avaliado classificou-se como $100 \%$ péssimo, devido às más condições de sinalização e desníveis, descontinuidades e rebaixamento inadequado das calçadas. Já o desempenho de acessibilidade das travessias das escolas estaduais, foi $16,67 \%$ excelente e $50 \%$ péssimo. 
Figura 2 - Acessibilidade dos pisos táteis das calçadas de acesso aos ginásios das escolas

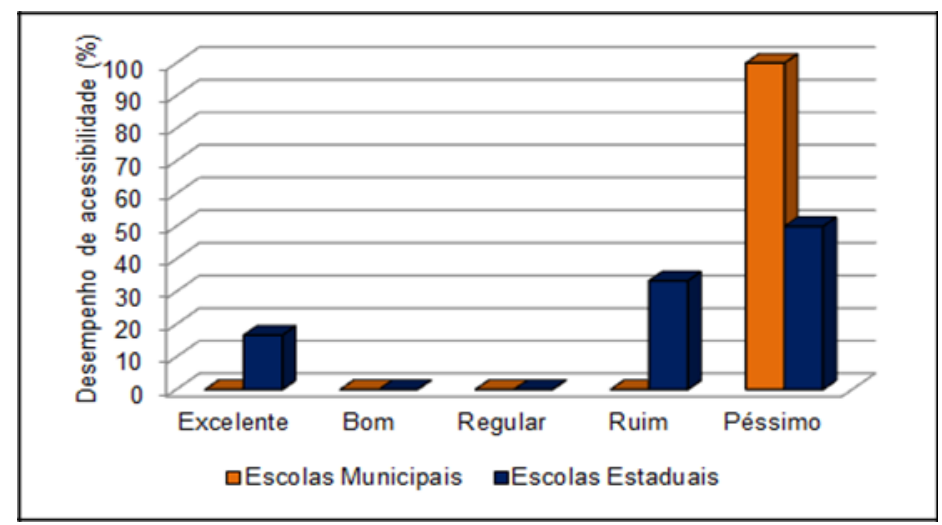

Fonte: Ariane e Vanessa (2018)

Figura 3 - Acessibilidade nas travessias de acesso aos ginásios das escolas

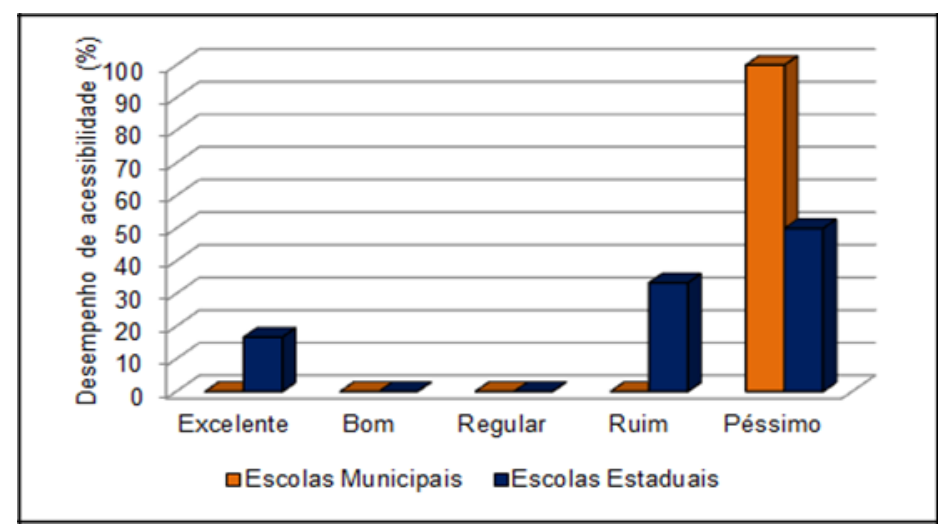

Fonte: Ariane e Vanessa (2018)

O desempenho de acessibilidade avaliado em relação ao mobiliário urbano nas calçadas de acesso ao ginásio de escolas municipais foi $100 \%$ péssimo (Figura 4). Isso ocorreu devido à falta de sinalização tátil de alerta em torno do mobiliário indicando a presença dos mesmos. Muitos estavam instalados fora da faixa de serviço, interrompendo o fluxo de pedestres e colocando em risco a segurança dos usuários. Nas escolas estaduais o item mobiliário urbano apresentou desempenho de $16,67 \%$ bom, mesmo assim não garantindo a total segurança, pois obteve $33,33 \%$ de desempenho péssimo.

Figura 4 - Acessibilidade dos Mobiliários Urbano das calçadas de acesso aos ginásios

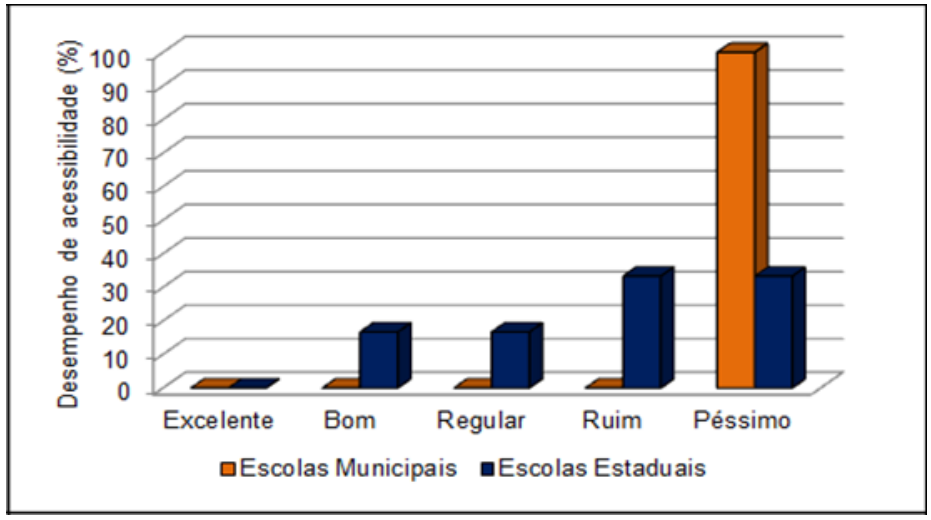

Fonte: Ariane e Vanessa (2018)

As escolas estaduais e municipais apresentaram desempenho de acessibilidade de $50 \%$ no 
item corredores internos dos ginásios. Porém, o desempenho de acessibilidade das escolas municipais apresentou-se como 50\% péssimo, devido à largura dos corredores ser menor que os 1,20 m, recomendados pela norma, e o piso liso, diferente do desempenho de acessibilidade das escolas estaduais, que apresentou desempenho de acessibilidade $16,67 \%$ regular, $16,67 \%$ ruim e $16,67 \%$ péssimo, conforme mostra Figura 5.

Figura 5 - Acessibilidade dos corredores internos dos ginásios das escolas

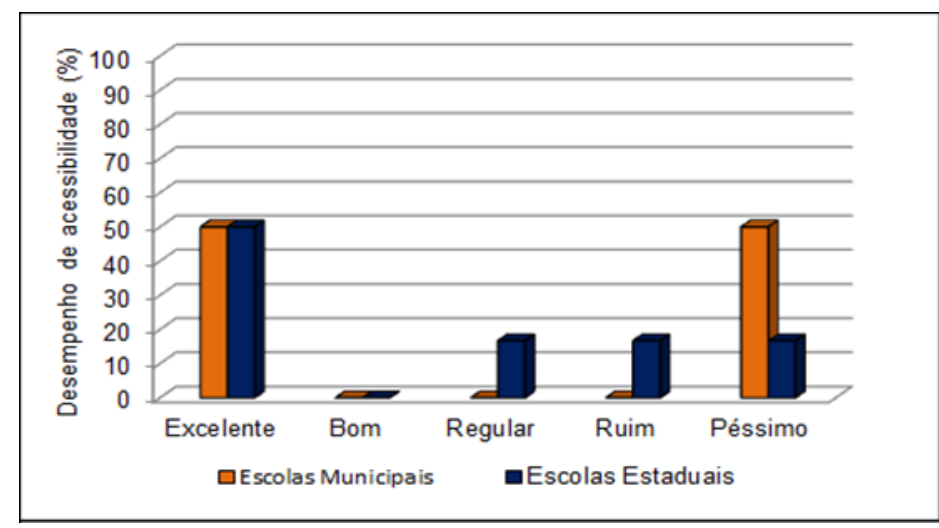

Fonte: Ariane e Vanessa (2018)

A acessibilidade dos sanitários internos dos ginásios das escolas municipais classificou-se com $50 \%$ péssimo e $50 \%$ ruim, pois não havia sinalizações táteis (alerta e direcional), ausência de barras de apoio nas laterais e no fundo dos vasos sanitários e dimensões inadequadas. Já o desempenho de acessibilidade dos sanitários internos dos ginásios das escolas estaduais foi $25 \%$ bom, pois atendia às dimensões estabelecidas pela norma, mas mesmo assim $75 \%$ destes estavam em péssimas condições, conforme mostra Figura 6.

Figura 6 - Acessibilidade dos sanitários dos ginásios das escolas

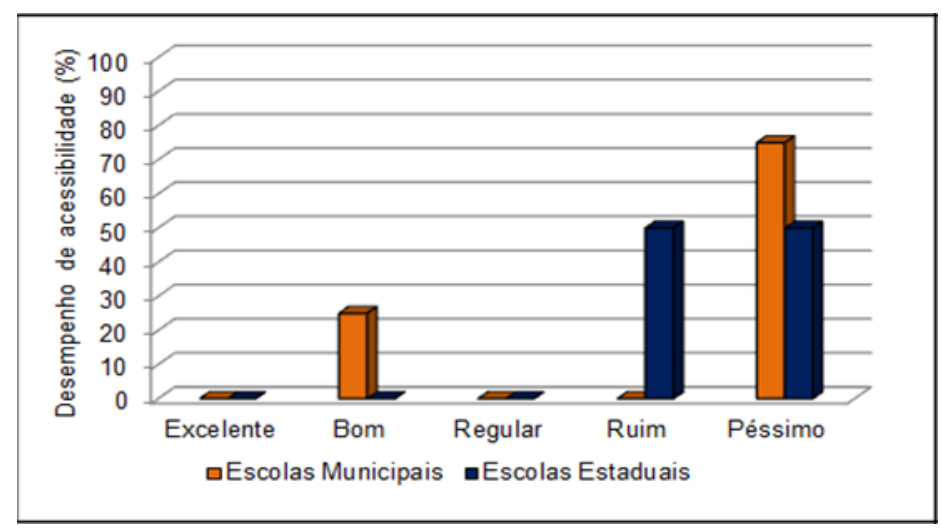

Fonte: Ariane e Vanessa (2018)

\section{CONCLUSÕES}

A escola pública que apresentou melhor desempenho de acessibilidade nos ginásios foi a escola estadual E, devido ao fato de atender os requisitos estabelecidos nas normas brasileiras sobre acessibilidade. Já os ginásios das escolas estadual F e municipal I, apresentaram pior desempenho de acessibilidade, pois não havia acessibilidade nos locais analisados.

Na avaliação de acessibilidade na parte interna dos ginásios, o pior desempenho foi relacionado à avaliação dos pisos táteis, não encontrados em nenhuma escola. Os corredores apresentaram melhor desempenho de acessibilidade, com 50\% dos ginásios das escolas estaduais e municipais classificados como excelentes, pois apresentaram as medidas mínimas estabelecidas pela norma. Na parte externa, as travessias de acesso aos ginásios e o mobiliário urbano das calçadas de acesso obtiveram o pior percentual de desempenho de 
acessibilidade, devido à falta de sinalização e más condições dos mesmos. Já o melhor desempenho de acessibilidade na parte externa foi obtido pelas travessias, ainda com desempenho de acessibilidade baixo, foi a que apresentou melhor desempenho se comparada aos demais itens.

Entretanto, nenhum ginásio das escolas estaduais classificou-se com desempenho excelente nos itens avaliados de acessibilidade, mas apresentaram melhor desempenho do que as escolas municipais. Os resultados mostraram que os ginásios de esportes das 10 escolas públicas avaliados no município de Chapecó (SC), não atenderam aos requisitos de acessibilidade mínima exigidos pelas normas brasileiras, impossibilitando as pessoas portadoras de deficiência física e mobilidade reduzida de executarem atividades físicas ou de participarem de eventos realizados nestes locais.

Portanto, a responsabilidade é dos órgãos públicos em projetar e adequar os espaços das escolas de acordo com as normas técnicas, incluindo os ginásios esportivos, possibilitando os mesmos direitos para todos.

\section{REFERÊNCIAS}

ABNT ASSOCIAÇÃO BRASILEIRA DE NORMAS TÉCNICAS. NBR 9050: Acessibilidade de Pessoas Portadoras de Deficiência a Edificações, Espaço, Mobiliário e Equipamento Urbano. Rio de Janeiro, 2015.

NBR 16537: Acessibilidade - Sinalização Tátil no Piso - Diretrizes para elaboração de projetos e instalação - Citações em documentos - Apresentação. Rio de Janeiro, 2016.

BERNAL, LUciana Mação. Acessibilidade em instalações esportivas em presidente prudente: a importância de um ambiente projetado para o deficiente físico. São Paulo 2012. $179 \mathrm{f}$. Monografia (Graduação em Arquitetura e Urbanismo). Faculdade de Ciência e Tecnologia da Universidade Estadual Paulista "Júlio de Mesquita Filho". 2012. Disponível em:

<http://www.unoeste.br/site/enepe/2012/suplementos/area/Humanarum>. Acesso em: 04 abr. 2018.

BRASIL. Estatuto da Cidade - Lei no 10.098, de 19 de dezembro de 2000. Estabelece normas gerais e critérios básicos para a promoção da acessibilidade das pessoas portadoras de deficiência ou com mobilidade reduzida, e dá outras providências. Diário Oficial da União. Brasília, DF, 19 dez. 2000. Disponível em:

<http://www.planalto.gov.br/ccivil_03/leis/L10098.htm>. Acesso em: 11 abr. 2018.

GADELHA Crismere. Ano Internacional das Pessoas Deficientes 1981-2011. Secretaria dos Direitos da Pessoa com Deficiência. Memorial da Inclusão 30 anos do AIPD. São Paulo: Imprensa Oficial do Estado de São Paulo, 2011. Disponível em:

<https://pt.scribd.com/document/121856705/Movimento-das-Pessoas-com-Deficiencia-noBrasil>. Acesso em 07 Jul. 2018.

MAZZOTTA, Marcos José da Silveira. Inclusão Social de Pessoas com Deficiências e Necessidades Especiais: cultura, educação e lazer. 2011 . 389 f. Artigo. Universidade de São Paulo. São Paulo 2011 . Disponível em: <https://www.scielosp.org/pdf/sausoc/201 1.v20n2/377389>. Acesso em: 05 abr. 2018.

MUZILLO, Pillar. Condições de acessibilidade urbana em passeios: análise em recorte da área central de Curitiba - Paraná. 2016. 191 f. Dissertação de Mestrado em Engenharia da Construção Civil, Universidade Federal do Paraná. Curitiba 2016. Disponível em:<http://acervodigital.ufpr.br/bitstream/handle/1884/45786/R\%20-\%20D\%20\%20PILLAR\%20MUZILLO.pdf? sequence=1 \&isAllowed=y>. Acesso em: 18 Jun. 2018. 